\title{
Maintaining education, research and innovation in orthopaedic surgery during the COVID-19 pandemic. The role of virtual platforms. From presential to virtual, front and side effects of the pandemic
}

\author{
Marius M. Scarlat ${ }^{1} \cdot$ Jing Sun ${ }^{2} \cdot$ Patricia M. B. Fucs ${ }^{3} \cdot$ Peter Giannoudis $^{4} \cdot$ Andreas F. Mavrogenis $^{5} \cdot$ Thami Benzakour $^{6}$. \\ Andrew Quaile ${ }^{7}$. James P. Waddell ${ }^{8}$
}

Published online: 16 October 2020

(C) SICOT aisbl 2020

Being physician or medical student is a complex task that became currently more subtle and difficult. On March 11, 2020 the World Health Organization (WHO) declared the global pandemic with the occurrence and spread of a potentially life-threatening virus named COVID-19 with over 100.000 cases in 100 different countries affected by that time [1]. The pandemic spread fast and at the time when this paper goes in print over one million humans died as a result of viral action or related complications and over 36 million were infected [2]. The need to control the spread of the virus imposed in many countries measures of confinement, lockdown and social distancing. The orthopaedic practice was deeply affected by the pandemic and all the work schedules were altered. Guidelines from professional associations $[3,4,5]$ proposed to postpone elective surgeries depending on the local situations and resources. The pandemic demonstrated the health system inequalities throughout the world, red lights turned

Marius M. Scarlat

mscarlat@gmail.com

1 Clinique Chirurgicale St Michel, Groupe ELSAN, Toulon, France

2 Orthopaedic Surgery Official Journal of the Chinese Orthopaedic Association, Tianjin, China

3 Department of Orthopaedic Surgery and Pediatric Orthopaedics, Santa Casa de Sao Paulo, Sao Paulo, Brazil

4 Trauma \& Orthopaedic Surgery, School of Medicine, University of Leeds, Leeds, UK

5 Orthopaedic Department, Kapadostrian University of Athens, Athens, Greece

6 Zerktouni Orthopaedic Clinic, Casablanca, Morocco

7 Spineworks, Hampshire Clinic, Basingstoke, Hampshire, UK

8 St Michael Hospital, Orthopaedic Surgery, University of Toronto, Toronto, ON, Canada on in many countries making visible how hard is to address such a global threat even in the twenty-first century.

The pandemic changed the world, in all aspects, but we don't know yet if for better or for worse. We are still far from the end of it. Dealing with the "new normal" is a stressful change, still a working process to all of us [6]. The teaching / learning, to all ages and grades and types of schools is altered in terms of methods, outcomes and results, learning could be affected with online classes, especially in the young age group of children and adolescents.

The medical school students were affected too. In many countries the theoretical part activities shifted to online in the preclinical years [7, 8]. New sophisticated tools are developed to measure the efficacy of the e-learning. The side effects could be compensated in the following school year if normality equals again physical participation in class and school activities. Limitations on the clinical environment impacts classes, case discussions, lectures, internships and clinical rotations [8], as a result entire groups of students missed months of educational experiences, fundamental to their training as doctors. Authors also recognize that emergency remote teaching may not contain all the best practices in effective online instructions $[9,10]$.

As the medical education environment is cross-generational [11] consequences in the long term in the process and career trajectory of this new generation of doctors will have to be evaluated. The advance in technology and communication achieved in these lasts months is substantial and pointed out the qualities of the virtual learning, many activities are now easier, accessible and faster and eventually this will show us that not all the traditional classes and lectures are compulsory in the medical curriculum. The Covid-19 pandemic pushed the orthopaedic surgeon to integrate technology to help in many activities. Web-based meetings, daily / weekly meetings were the way to keep us connected, inside departments and among institutions. New platforms are now our work methods. In the 
future, medical education may migrate to a hybrid model with webinars and virtual meetings completed with traditional clinical and presential activities, more flexibility and adaptation being needed.

In normal times, it would be impossible to follow the huge amount of webinars / courses / lectures available in all specialties. Nevertheless, current schedules are flexible which allow everyone to access these platforms. Technology is a powerful tool today and a supplement not a replacement in the training process. We have to be aware that having more information is not learning more. Online watching is not online learning.

We also lost our meetings, courses and congresses that were a part of our academic and work activity, we experienced loss of personal interaction and we miss asking questions and sharing experiences with speakers and experts [12]. No doubt that virtual meetings are better than nothing and in the future "hybrid meeting" may become popular.

The clinical practice changed with fewer patients seen and decreased numbers in all health systems. In the emergency trauma cases the first moments of lockdown resulted in very few cases but the numbers increased rapidly in the following months, especially with bikes and motorcycles accidents [13]. The oncology patients could not be postponed either. We observed a substantial backlog of elective surgeries and patients reticence for going to the hospital. The physicians' activity and incomes were altered. The adoption of telemedicine started this year in many countries and is increasing. We were used to exchange information using videocalls but not familiar with non-presential consultations. The fundamental change in the reimbursement of these online consultations increased the communication as shown with the higher numbers of video / telephone visits measured from March to May 2020 in a study. In the author's opinion, the use of telemedicine will continue in the post-pandemic era, although we also agree that telemedicine facilitates the care but does not appear to replace inperson clinics [14].

At this critical time, almost all major congress meetings, symposia or seminars, including medical meetings at national or regional levels are cancelled or postponed.

Technology is constantly changing the face of science in various aspects, particularly in dissemination and interpretation of academic knowledge and outcomes [15]. Considering the high virulence of COVID-19, difficulty in travelling across countries and cities, inappropriateness of gathering a crowd, as well as new findings, theories and technologies for example, in the field of orthopaedics are emerging and should be shared $[16,17,18,19,20]$; in this scenario, organizing virtual meetings instead of conventional ones using virtual conferencing system/platform seems safe and efficient.

Virtual conferencing system/platform is realized by network communication technology, which supports people to carry out real-time information communicating and sharing from remote distance. Compared with traditional meetings, virtual meetings have even more applications with superiority in many ways, and the situation for medical science is especially so. Virtual meetings become essential for medical scientists to carry out academic communication, teaching activities, medical consultations and even remote ward rounds for quarantined patients. Holding virtual meetings could actually solve a series of issues that the well-established traditional format includes such as time and costs consumed in traveling, impossibility to attend several meetings in different places in the same time, limitations in participation due to space and accessibility.

Medical meetings and events play an important part in the healthcare and pharmaceutical industry. Until the beginning of 2020, attending a meeting required physical presence. During the COVID-19 pandemic, virtual meetings are becoming the norm in medicine but also in industry, business and management. The benefits of such meetings include time saving, elimination of travel expenses and accommodation, improved access with possibility to appoint presenters and attendants irrespective of geography or remote areas. Additionally, virtual meetings can be held over days and weeks so that registrants can participate around their schedules, they can attract larger audiences from around the world and accommodate different languages using subtitles in lectures to better transfer of knowledge and learning experiences. Virtual meetings offer greater flexibility compared to in-presence meetings and will probably become a part of our routine even after the end of the virus threat.

Important demerits and concerns exist with virtual meetings [21]. Through the Internet, it is not easy "to discriminate between genuine insight and deliberate invention". Moreover, as an information resource, the Internet completely lacks quality controls. The context deficit and privacy issues are additional drawbacks, and there is always the risk that the contents may not be correct, even if the original sources were reliable. A rigorous peer-review system is the solution to these problems in virtual meetings as well $[22,23]$. The need for the necessary equipment for virtual meetings such as hardware, software and online connection, as well the familiarity with new technology are prerequisites for virtual meetings.

Attending a presential meeting means "go to places, meet people and do things"; Virtual meetings can be accessed from office or from home with no more need to travel or accommodate. These may be a relief for some, usually the younger and active workers, but a distress for others. In a virtual meeting, personal relationships, trust and reliance are difficult to develop. The physical and emotional reactions to information and events during the meeting are difficult to detect. Presenters and attendants are more easily distracted by events around them in their remote location. Misunderstandings due to differences in culture and language, which are common in traditional meetings, are more pronounced in virtual ones. 
Managing information overload is another concern with virtual meetings. Therefore, there is a risk that virtual meetings will have lower quality and will be effective only when the matters are routine and the decisions are easy to reach.

Planning a virtual meeting requires assembling a group of dedicated and experienced people with different roles to assist all aspects of meeting; planning and organization are paramount and will eventually ensure the smooth and orderly running of the meeting. The choice of a secure, universal and user-friendly webinar platform is important. There are numerous platforms on the market with different prices and features and the choice for the virtual meeting platform in terms of your budget and demand is crucial. Well-received international professional platforms include GoToMeeting, Zoom, ClickMeeting, Adobe Connect, or other online communication toolsets. Free platforms include TeamViewer, Google hangouts, Anymeeting and many more. Evaluating and comparing the available platforms before committing to one specific could be helpful [24].

Conference confidence and security is a major concern. The healthcare industry handles sensitive information, therefore it is important to know that this data is well protected. The virtual meeting provider should have measures in place that will allow conducting the meeting to the highest industry standards and complying with data protection and privacy legislation. This includes being able to lock your conferences or requiring a password to enter.

The success of a meeting majorly relies on the presentations of invited speakers, thus an initial invitation message should be send to the experts in early time to strive for their availability and avoid scheduling conflicts. A further formal invitation should be drafted for the invited presenters including theme, date and time of the meeting, template to capture slides, abstracts, biographies and photos. Considering the nature of virtual meeting, user introduction of webinar software as well as important documents such as consent of recording during meeting, permission to host the virtual meeting through system or platform publicly, and other related incenses should be required. The virtual meeting announcement should reach the public. Since there is no space limit, an announcement including meeting information and highlights could be disseminated to attract more audience. Popular social media are excellent channels to announce the meeting, and mailing lists targeting the relevant audience are very useful. Marketing platforms or companies are alternative options to increase visibility as well. Tracking virtual meeting attendance is another concern, particularly in large-scale meetings and meetings with patients that need to be kept on record. Attendance reports will allow to keep track of who has attended the meetings, when, which sessions and for how long.

The Real-time interaction during virtual meeting is essential. The meeting should leave some time for questions, answers and interaction between onsite and online attendees.
Discussions and debates regarding the meeting can also be launched on social media to attract more people to participate.

The post webinar feedback is a good method for evaluating the results of communication. Every meeting has room for improvement. Was the meeting too long? Were the items on the agenda unclear? Did one person dominate the discussion? No matter what the problem is, you cannot start to solve it until you know it exists. Be sure to get feedback about what went well and what didn't did not for every attendee. Through the online meeting platform, use a simple survey, or engage in informal online conversations with attendees after the meeting to solicit their opinions and feed-back (Fig. 1).

The future and what we expect? COVID-19 infection has provided an opportunity to reconsider medical meetings. Present and future education faced new challenges and opportunities. Virtual educational resources are numerous and are expected to increase more. The advent of advanced network technologies such as the fifth generation (5G) wireless systems, where available, further enhance the visual experience by transmitting high quality images and sound closer to the reality in a speedy and stable manner so that the attendees acquire information or deliver contributions to the scientific event simply by their phones without moving from their offices. The major limitation of this form of meeting is that it lacks of contact, emotion and affection among attendees, which can only be obtained when meeting in person. Hence, an ideal virtual meeting integrated with more humanity by advanced technology such as virtual reality (VR) technology (i.e. VR technology) is to be expected and also to be evaluated.

With ethos of diversity and equality, and foreseeing a continuous virtual medical education, SICOT has officially announced and currently conducting the SICOT Virtual Education Program 2020 after approval by the SICOT Executive Committee and Board of Directors. It consists of a series of webinars, webcasts and podcasts, surgical tips and techniques on variable Orthopaedic surgery by key opinion leaders with high skills in their area of specialization. The SICOT Programme of Innovative Orthopaedic Networking, e-learning, Education and Research (SICOT-PIONEER) is free for all the SICOT members, along with the publication of resources and research stored in a user friendly repository. It allows the opportunity to participate in e-learning modules, recorded lectures and interactive discussion boards on different virtual platforms. This will be a chance for everyone, in the most remote geographic areas of the world to remain up-todate with surgical techniques, stay on track with their professional development and remain connected to a supportive network of like-minded surgeons in these uncertain times. Importantly, this virtual program is intended to be carried forward into the future, beyond COVID-19 [25].

Virtual clinics are another aspect of changes in our practice. The research starts and ends to the patients. Therefore, virtual 


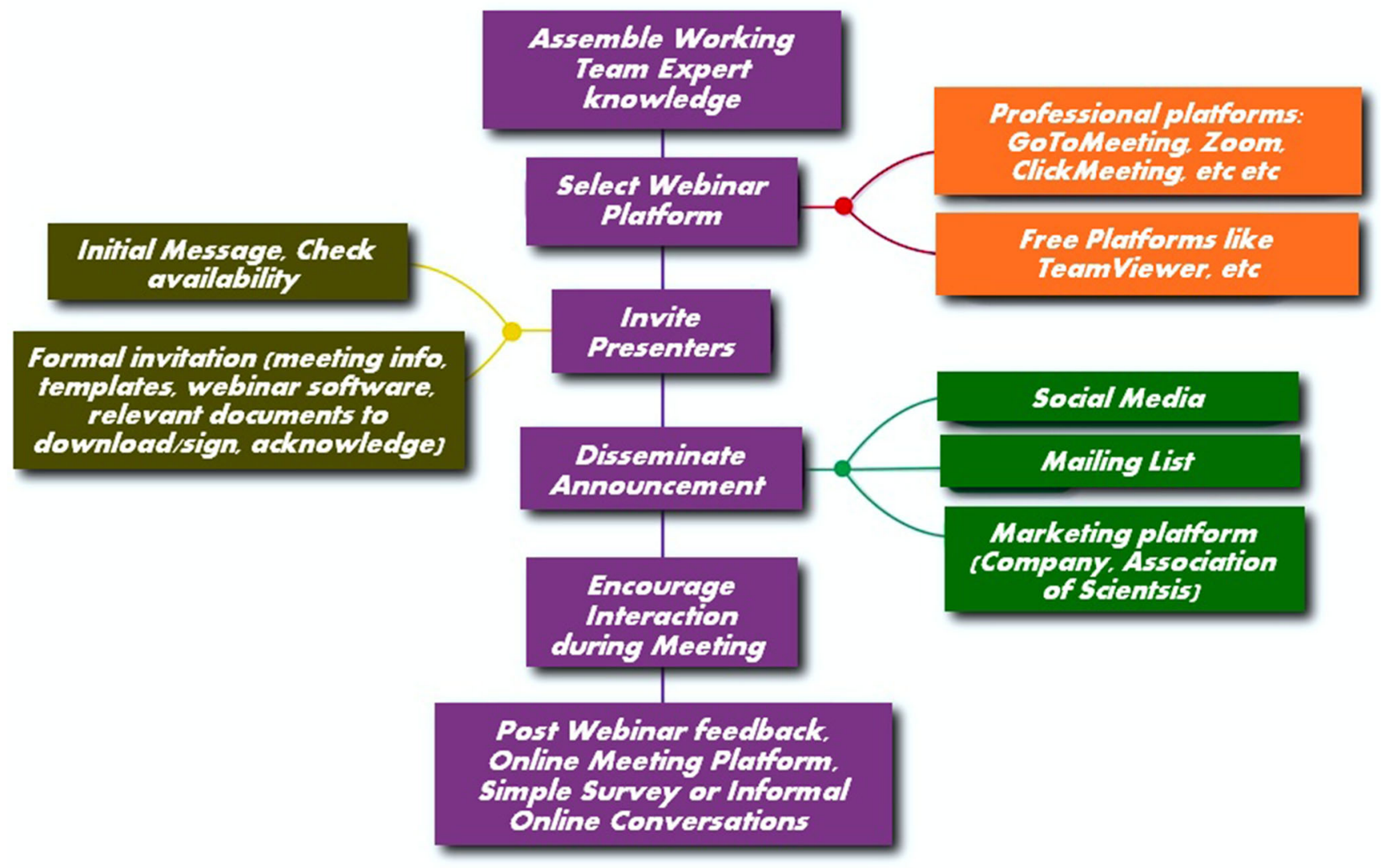

Fig. 1 Flowchart of planning and organization of virtual meeting

meetings and clinics should be expected to benefit the patients. Doctors and nurses will have improved access to patients and information, and patients will experience greater convenience and more visibility. Virtual visits and care will be especially convenient if the patients live far away, are elderly or disabled, and will probably allow for more timely interventions. However, even if the medical care can be effectively accomplished by virtual prescriptions and avoidance of unnecessary referrals, we doubt on the effectiveness and quality of the virtual nursing.

In Clinical practice the COVID-19 pandemic has forced a shift to virtual care models in order to reduce patient exposure to high-risk environments and to preserve valuable health care resources.

Going virtual is the exception becoming a routine. In clinics at the beginning of the pandemic the activity decreased significantly. Many previous patients simply didn't show up for periodic check consultations as they were used. Non urgent surgical cases dropped to about $7 \%$ in many locations. New patients at office became rare. At the end of the lockdown, the number of patients increased to about half of the usual. Emergencies number (mainly after traffic injuries) also decreased by about $40 \%$ in comparison with the same time frame of previous years. Such a drastic move of the presence was obviously due to the total or partial lockdown.
Trauma patients in times of pandemic are also potential COVID-19 carriers; this makes the treating orthopaedic surgeons the front-line treating physicians and the diagnostic methods as well as the protective measures had to adapt to this reality $[26,27]$.

In addition, the potential benefits of virtual practices are clear. For patients concerned telemedicine can address questions, coordinate testing and triage clinical needs. In rapidly adopting virtual clinics, our goal was to minimize the risk and the number of routine consultations [28].

We have convened during our virtual consultations, mainly thanks to a national doctors call platform, that we should give appointments for elective procedures only when possible and reasonable. The hospital is also required to have the capacity to admit non-COVID patients to a separated area with effective personal protection equipment, testing kits for the virus, with social distancing in all phases. In doubt, recommendation to all the staff was to treat all patients as if they were potentially infected or at high risk [29] Outpatient visits for nonurgent chronic diseases were postponed or performed through local or national telemedicine platforms. During the video or smartphone consultation, we concentrate on making a careful selection of the elective surgeries because of the growing waiting list. Telemedicine sessions are helpful with patients follow-up. 
In this crisis, we felt a certain satisfaction from patients and staff, but does transition to virtual care really reduces transmission of COVID-19? Our guiding recommendations in terms of practice and caring for patients were focused during lockdown on postponing or cancelling all planned elective surgeries and clinic visits and switch patient examinations to telemedicine [30]. The responsibility of a medical doctor remains to provide medical information and transfer knowledge despite casualties [31].

In the current mediatic era, orthopaedic surgeons need to refocus some of their time and energies from surgery to communication and constructive research and virtual platforms are a part of this change $[32,33]$.

\section{References}

1. WHO. Coronavirus disease 2019 (COVID-19) situation report-51. 2020; https://www.who.int/docs/default-source/coronaviruse/ situation-reports/20200311-sitrep-51-covid-19.pdf?sfvrsn= 1 ba62e57 10

2. https://www.nytimes.com/interactive/2020/us/coronavirus-uscases.html Accessed online, October 02, 2020

3. AAOS. AAOS Clinical Considerations During COVID-19. 2020; https://www.aaos.org/globalassets/about/covid-19/aaos-clinicalconsiderations-duringcovid-19.pdf. Accessed September 25, 2020

4. Guy DK, Bosco III JA, Savoie III FH (2020) AAOS Guidelines for Elective Surgery During the COVID-19 Pandemic. 2020; https:// www.aaos.org/about/covid-19-information-for-our-members/aaosguidelines-for-elective-surgery/ Accessed September 25

5. ACS. COVID-19: Recommendations for Management of Elective Surgical Procedures. 2020; https://www.facs.org/covid-19/ clinicalguidance/electivesurgery Accessed September 25, 2020

6. Khanduja V, Scarlat MM (2020) Reaching a new 'normal' after COVID pandemic and orthopaedic implications. Int Orthop 44(8): 1449-1451. https://doi.org/10.1007/s00264-020-04725-4

7. Wayne DB, Green M, Neilson EG (2020) Medical education in the time of COVID-19. Sci Adv 6(31):eabc7110. https://doi.org/10. 1126/sciadv.abc7110

8. Gill D, Whitehead C, Wondimagegn D (2020) Challenges to medical education at a time of physical distancing. Lancet 396(10244): 77-79. https://doi.org/10.1016/S0140-6736(20)31368-4

9. ASSOCIATION OF AMERICAN MEDICAL COLLEGES. Important guidance for medical students on clinical rotations during the coronavirus (COVID-19) outbreak. Press release March 17, $2020 \mathrm{https}: / / \mathrm{www}$. aamc.org/news-insights/press-releases/ important-guidance-medical-students-clinical-rotations-duringcoronavirus-covid-19-outbreak Accessed October 4, 2020

10. Wong RY (2020) Medical education during COVID-19: lessons from a pandemic. BCMJ 62(5):170-171

11. Rose S (2020) Medical student education in the time of COVID-19. JAMA. 323(21):2131-2132. https://doi.org/10.1001/jama.2020. 5227

12. Plancher KD, Shanmugam JP, Petterson SC (2020) The changing face of orthopaedic education: searching for the new reality after COVID-19. Arthoscopy, Sports Medicine, and Rehabilitation 2(4): e295-e298

13. Ambrosio L, Vadala G, Russo F, Papalia R, Denaro V (2020) The role of the orthopaedic surgeon in the COVID-19 era: cautions and perspectives. J Exp Orthop 7:35. https://doi.org/10.1186/s40634020-00255-5
14. Rizzi AM, Polachek WS, Dulas M, Strelzow JA, Hynes KK (2020) The new "normal": rapid adoption of telemedicine in orthopaedics during the COVID-19 pandemic. Injury. https://doi.org/10.1016/j. injury.2020.09.009

15. Desai AN, Patel P (2020) Stopping the spread of COVID-19. JAMA 323(15):1516. https://doi.org/10.1001/jama.2020.4269

16. Scarlat MM (2019) General and specialized Orthopaedics. Int Orthop 43:1037-1039. https://doi.org/10.1007/s00264-01904333-x

17. Mavrogenis AF, Scarlat MM (2019) Surgeons and robots. Int Orthop 43:1279-1281. https://doi.org/10.1007/s00264-01904345-7

18. Tian W, Liu YJ, Liu B et al (2019) Guideline for thoracolumbar pedicle screw placement assisted by Orthopaedic surgical robot. Orthop Surg 11(2):153-159

19. Wu XB, Wang JQ, Sun X, Zhao CP (2019) Guidance for treatment of pelvic acetabular injuries with precise minimally invasive internal fixation based on the orthopaedic surgery robot positioning system. Orthop Surg 11(3):341-347

20. Zhang XJ, Zhu YB, Liu S et al (2019) Incidence of low-energy upper extremity fractures and the risk factors in Chinese people 50 years or older. Orthop Surg 11(2):304-310

21. Porpiglia F, Checcucci E, Autorino R et al (2020) Traditional and virtual congress meetings during the COVID-19 pandemic and the post-COVID-19 era: is it time to change the paradigm? Eur Urol 78(3):301-303

22. Fadlelmola FM, Panji S, Ahmed AE, Ghouila A, Akurugu WA, Domelevo Entfellner JB, Souiai O, Mulder N H3ABioNet Research working group as members of the H3Africa Consortium (2019) Ten simple rules for organizing a webinar series [published correction appears in PLoS Comput Biol. 2019 May 8; 15(5):e1007048]. PLoS Comput Biol. 2019; 15(4):e1006671. https://doi.org/10. 1371/journal.pcbi.1006671

23. Loeb AE, Rao SS, Ficke JR, Morris CD, Riley LH 3rd, Levin AS (2020) Departmental Experience and Lessons Learned With Accelerated Introduction of Telemedicine During the COVID-19 Crisis. J Am Acad Orthop Surg 28(11):e469-e476. https://doi.org/ 10.5435/JAAOS-D-20-00380

24. Review of online meeting and webinar software. Available from: https://webconferencing-test.com Accessed on October 04, 2020

25. SICOT PIONEER https://www.sicot.org/pioneer accessed October 04, 2020

26. Parvizi J, Gehrke T, Krueger CA, Chisari E, Citak M, Van Onsem S, Walter WL (2020) Resuming elective Orthopaedic surgery during the COVID-19 pandemic: guidelines developed by the international consensus group (ICM). J Bone Joint Surg Am 102(14): 1205-1212. https://doi.org/10.2106/JBJS.20.00844

27. Mehrotra A, Ray K, Brockmeyer DN, Barnett ML, Bender JA (2020) Rapidly converting to "virtual practices": outpatient care in the era of Covid-19 April 1. https://doi.org/10.1056/CAT.20. 0091

28. Spelman JF, Brienza R, Walsh RF, Drost P, Schwartz AR, Kravetz JD, Pitkin P, Ruser C (2020) A model for rapid transition to virtual care, VA Connecticut primary care response to COVID-19. J Gen Int Med 1-4. Advance online publication. https://doi.org/10.1007/ s11606-020-06041-4

29. Mavrogenis AF, Quaile A, Scarlat MM (2020) The virus crisis affects Orthopaedic surgery and scientific activities worldwide. International Orthopaedics (SICOT) 44:813-817. https://doi.org/ 10.1007/s00264-020-04557-2

30. Mc Michael TM, Clark S, Pogosjans S, Kay M, Lewis J, Baer A et al (2020) COVID-19 in a long-term care facility, kings county, Washington. February 27-march 9 2020. Center for Disease Control and Prevention, Morbidity and Mortality Weekly Report (MMWR) 69(12):339-342. https://doi.org/10.15585/mmwr. mm6912e1 
31. Agha Z, Lofren RP, VanRuiswyk JV, Layde PM (2020) Are patients at veterans affairs medical centers sicker? A comparative analysis of health status and medical resource use. Arch Intern Med 160(21):3252-3257. https://doi.org/10.1001/archinte.160.21. 3252

32. Vannabouathong C, Devji T, Ekhtiari S, Chang Y, Phillips SA, Zhu M, Chagla Z, Main C, Bhandari M (2020) Novel Coronavirus COVID-19: Current Evidence and Evolving Strategies. J Bone Joint Surg Am 102(9):734-744. https://doi.org/10.2106/JBJS.20. 00396
33. Romanò CL, Drago L, Del Sel H, Johari A, Lob G, Mavrogenis AF, Benzakour T, World Association against Infection in Orthopedics and Trauma (WAIOT) Study Group On Bone And Joint Infection Definitions (2020) Loud and silent epidemics in the third millennium: tuning-up the volume. Int Orthop 44(6):1019-1022. https://doi. org/10.1007/s00264-020-04608-8

Publisher's note Springer Nature remains neutral with regard to jurisdictional claims in published maps and institutional affiliations. 